\title{
CONCEPÇÕES DE LETRAMENTO SUBJACENTES EM UM MATERIAL DIDÁTICO DE PORTUGUÊS LÍNGUA DE ACOLHIMENTO (PLAC)
}

\author{
Laura Fontana Soares \\ Universidade Federal do Rio Grande do Sul \\ Gabrielle Sirianni \\ Universidade Federal do Rio Grande do Sul
}

\section{RESUMO}

Tendo em vista a necessidade de se aprimorar o ensino de Português Língua de Acolhimento (PLAc), neste trabalho analisamos os conceitos de leitura e de escrita subjacentes às tarefas e atividades da apostila Portas Abertas (REINOLDES; MANDALÁ; AMADO, 2017), pensando em como os alunos são preparados para o uso social da escrita e da leitura por meio deste material didático. $\mathrm{Na}$ metodologia de análise, definimos critérios que incidem sobre aspectos da apostila, como gêneros discursivos escolhidos e seu tratamento nas tarefas que guiam o trabalho com o texto, a partir das orientações trazidas em Bulla, Lemos e Schlatter (2012). Foi possível identificar, por meio do enfoque em uma das unidades didáticas, tarefas alinhadas ao modelo de letramento autônomo, bem como outras alinhadas ao modelo de letramento ideológico (KLEIMAN, 1995; STREET, 2003), resultados que sublinham os pontos positivos do material didático, além de indicarem aspectos a serem potencializados por meio de reformulações de atividades e criação de tarefas didáticas. A partir da leitura crítica deste material didático, ressaltamos a importância de apostilas de PLAc virem acompanhados por caderno do professor, com vistas a auxiliar o docente a conciliar os percalços que são encontrados nesse contexto, além de promover um ensino de língua com vistas à participação cidadã dos imigrantes deslocados forçados.

PALAVRAS-CHAVE: Letramento; Material Didático; Português como Língua de Acolhimento. 


\section{Introdução}

Ao determos nossa atenção sobre o espaço ocupado pelos livros didáticos (LD) no Brasil, no espectro amplo do ensino de português como língua materna ou adicional, é necessário refletir sobre a importância desses materiais na sala de aula, bem como sobre o uso que deles é feito pelo professor. Nas palavras de Rojo (2013), ao discorrer sobre materiais didáticos no ensino de línguas, os livros didáticos estruturam o trabalho pedagógico de ensino, orientando o que e como os conteúdos serão ensinados, tendo sua importância alçada a de uma metodologia de ensino. Este papel central desempenhado pelos materiais didáticos justifica o trabalho investigativo sobre eles, que pode ser centrado em diferentes facetas, relacionando-se ao seu uso em sala de aula ou na análise de tarefas e enunciados que estabelecem orientações para professores e alunos. Ao selecionarmos o contexto de Português como Língua Adicional (PLA), encontramos um número reduzido de análises de materiais didáticos (SILVA, 2010) e quando afunilamos este contexto ao ensino de Português como Língua de Acolhimento (PLAc), tanto os materiais didáticos quanto suas análises são ainda mais escassas (OLIVEIRA, 2017).

Tendo em vista esse cenário, a análise de materiais didático se faz pertinente, entre outros aspectos, ao investigar quais as concepções de ensino que estão implicadas nas tarefas propostas aos aprendizes e sobre o uso que o professor fará de tal material. Neste artigo, analisamos a apostila didática Portas Abertas (2017), disponível gratuitamente para download, publicizada no último semestre de 2017. Este material se propõe ao ensino de português para imigrantes deslocados forçados, finalidade que o caracteriza como pertencente ao contexto de Português como Língua de Acolhimento.

Para realizar esta análise, primeiramente discorremos sobre os modelos de letramento ideológico e autônomo, propostos por Street (1984; 2003) e retomados por Kleiman (1995). Considerando o público de ensino ao qual o material se destina, valemo-nos da discussão sobre acolhimento em línguas (ANUNCIAÇÃO, 2017), para fundamentar nossa concepção sobre quais os modelos de tarefas de ensino mais apropriados a este perfil de aprendizes. A fim de orientar nosso trabalho analítico, explicitamos os critérios utilizados na análise das tarefas, com base naqueles estabelecidos por Bulla, Lemos e Schlatter (2012), e retomados por Oliveira (2017). Após a discussão teórico-metodológica, realizamos a análise dos temas 
das unidades do material, bem como de uma unidade em sua extensão; este movimento objetiva elucidar os conceitos de letramentos autônomo e ideológico e de, secundariamente, sugerir aprimoramentos na apostila Portas Abertas (2017), sem deixar de apontar o mérito de sua produção, por ser um material de livre acesso e engajado com o acolhimento linguístico de imigrantes e refugiados no Brasil.

\section{Concepções de letramento}

De acordo com Kleiman (1995), podemos definir o letramento como um conjunto de práticas sociais que usam a escrita, enquanto sistema simbólico e enquanto tecnologia, em contextos específicos, para objetivos específicos (KLEIMAN, 1995, p. 19); este entendimento apresenta-se em consonância com a concepção freiriana de alfabetização como processo de desenvolver a consciência crítica juntamente à tecnologia da leitura e da escrita (FREIRE, 1991). Rojo (2009, p. 98) também compreende por letramento "os usos e práticas sociais de linguagem que envolvem a escrita de uma ou de outra maneira, sejam eles valorizados ou não valorizados, locais ou globais, recobrindo contextos sociais diversos (família, igreja, trabalho, mídias, escola etc.), numa perspectiva sociológica, antropológica e sociocultural". As autoras, bem como outros teóricos que se ocupam do letramento, foram influenciados pelo autor britânico Brian Street e pelos Novos Estudos do Letramento (STREET, 1996).

Os dois modelos de letramento que apresentaremos a seguir foram propostos por Brian Street em seu livro Literacy in Theory and Practice (1984). O primeiro deles, o modelo autônomo de letramento, concebe que há apenas uma maneira de o letramento ser desenvolvido. Nesse viés, entende-se a escrita como um produto completo em si mesmo, neutro e que não depende do seu contexto de produção para existir. Nele, há somente uma leitura possível de textos que, coincidentemente, é aquela das comunidades de práticas privilegiadas econômica e socialmente (KLEIMAN, 1995). O modelo autônomo é o modelo dominante na agência de letramento da escola, na mídia e nos discursos políticos, que estabelecem a escrita como tecnologia essencial para o desenvolvimento cognitivo, econômico e social. De acordo com esse modelo, ao introduzir o letramento aos iletrados, será garantido a eles aumento cognitivo, econômico e se tornarão cidadãos ao dominarem a leitura e a escrita, sem considerar a situação sociocultural para a sua falta de letramento (STREET, 2003, p. 77). Dessa maneira, os grupos letrados 
são considerados pela sociedade como a norma, o esperado, o desejado.

Em contrapartida a esse modelo, Street (1984) propõe o modelo ideológico de letramento, que concebe as práticas envolvendo a leitura e a escrita como situadas e determinadas pelo contexto sociocultural dos indivíduos e, portanto, os significados específicos que a escrita assume para um grupo social dependem do contexto em que ela foi adquirida (KLEIMAN, 1995). De acordo com Street, o modelo ideológico de letramento oferece uma visão mais culturalmente sensível em relação às práticas de letramento, uma vez que elas variam de um contexto para o outro (STREET, 2003, p. 77).

A partir dos conceitos de letramento como prática social, modelo autônomo e modelo ideológico de letramento (KLEIMAN, 1995; STREET, 2000, 2003, 2009), propomos a análise das concepções de letramento subjacentes no material didático. Tais autores e os conceitos por eles mobilizados guiam a discussão sobre tarefas de ensino de língua portuguesa; partimos do entendimento de que tarefas que promovem o letramento com vistas para a participação social dos aprendizes, focadas no estudo de gênero discursivos em suas diversas facetas, viabilizam um letramento ideológico desejável, pois dessa maneira se possibilita a reflexão sobre o contexto do qual o texto faz parte. Em outras palavras, consideramos como "tarefas de ensino que partilham dos pressupostos do letramento ideológico" aquelas que buscam levar o aluno a compreender as práticas sociais que envolvem os textos. Ainda no que se refere ao letramento ideológico, desejável nas orientações de materiais didáticos, compreendemos que o acesso a textos vindos de contextos autênticos, que circulam no mundo, possibilita aos alunos uma aprendizagem crítica e com vistas à participação cidadã. Nesses termos, o uso da linguagem em situações similares às da vida real, na sala de aula, dá o aprendiz mais preparo para agir no mundo (CLARK, 2000). Dedicamos a seção seguinte à discussão sobre Português Língua de Acolhimento, a fim de contextualizar as fundamentações teóricas da área.

\section{Brasil como país acolhedor e ensino da língua portuguesa}

No contexto de ensino de português a imigrantes deslocados forçados, emerge o conceito de Português Língua de Acolhimento, representado pela sigla PLAc. De acordo com Grosso (2010), há definições consistentes sobre o ensino e aprendizagem de segunda língua (L2) e língua estrangeira (LE), se comparado com o estado da arte da produção didática 
e teórica sobre PLAc; tendo em vista seu caráter incipiente, o termo ainda se encontra em processo de redefinições e ajustes, carecendo de reflexões. Grosso (2010) ainda ressalta que há semelhanças entre os termos L2, LE e Língua de Acolhimento, contudo, este surge devido a mudanças sociais e ao processo dinâmico de globalização, uma vez que ultrapassa a motivação turística ou acadêmica de aprendizado da língua. No tocante à nomenclatura, pode-se compreender a perspectiva acolhedora como facilitadora do convívio social e condutora da integração em um novo espaço de vivências, em que o seu domínio é concebido como via para a integração e para a equidade social (ANÇA, 2003; CABETE, 2010).

Muito embora a nomenclatura "Língua de Acolhimento" remeta, em um primeiro momento, a um conceito benéfico e imprescindível nas situações de migração forçada, é preciso complexificar seu caráter de uso e repensar suas implicações, como aponta a recente e perspicaz análise de Anunciação (2017, p. 33). Nas palavras da autora:

Acolhimento é uma palavra de conotação positiva. Dificilmente alguém poderá afirmar que, no contexto de migração e refúgio, acolhimento seja desnecessário. $\mathrm{O}$ termo Língua de Acolhimento, no entanto, é problemático. (...) o conceito Língua de Acolhimento, enquanto política linguística do Estado português, é simbolicamente bastante violento, pois o acesso a direitos, como nacionalidade e autorização de residência permanente, é condicionado à comprovação de proficiência em língua portuguesa.

Ao problematizar este conceito, Anunciação (2017) focaliza o ensino de PLAc no país lusitano, que é garantido pelo programa Portugal Acolhe, cuja finalidade é promover a integração dos imigrantes, tendo como uma das frentes de ação o ensino de português. Uma das críticas feitas pela autora, referente ao programa Portugal Acolhe, diz respeito a sua divisão em módulos que separam o estudo da língua do estudo de cultura e cidadania, demonstrando, assim, uma concepção de ensino de língua que não condiz com um letramento ideológico e emancipador para os aprendizes (STREET, 1984; 2003), pois dissocia a linguagem de seu caráter social e histórico (BAKHTIN, 1997). Além disso, a pesquisa etnográfica com imigrantes realizada por Anunciação (2017) aponta para um acolhimento que não ocorre somente em português, mas que partilha espaço com as línguas de socialização presentes no repertório linguístico dos recém-chegados, remetendo a uma definição de acolhimento translíngue (CANAGARAJAH, 2013, citado em ANUNCIAÇÃO, 2017). 
Outra particularidade que caracteriza o acolhimento em línguas é a condição psicossocial do refúgio. Como afirma Grosso (2010, p. 65), "raramente alguém deixa o seu espaço de afetos se não tiver uma forte motivação que passa muitas vezes pela própria sobrevivência", situação dos imigrantes forçados, que, na maioria dos casos, têm urgência em ganhar dinheiro para sobreviver e para enviá-lo àqueles que ficaram em seus países de origem, ou para trazer suas famílias para junto de si; ou, ainda, aqueles que perderam seus familiares e vivenciam o luto.

Para dar conta de compreender as características particulares, que distinguem o PLAc do PLA e do PLE, diversos estudos de caso e trabalhos etnográficos foram empreendidos nos últimos anos, com destaque para os de Anunciação (2017), São Bernardo (2016) e Lopez (2016). Tais investigações apontam percalços em comum no ensino de PLAc, como a não frequência dos estudantes, professores voluntários sem formação para o ensino de línguas, carência de material didático e turmas cujos alunos possuem níveis de proficiência significativamente heterogêneos. Compartilhando dessas dificuldades em seu espaço pedagógico, Ruano e Cursino (2015) nomeiam este contexto de "porta-giratória", em que o aluno inicia o curso de português em qualquer momento do semestre e cuja abordagem de ensino é por tarefas comunicativas (ELT), organizadas em atividades por blocos com início, meio e fim em cada encontro, a fim de permitir que os estudantes tenham progresso na aprendizagem mesmo que não atendam regularmente às aulas.

Ainda sobre as características do PLAc, já apontadas por outras pesquisadoras (AMADO, 2013; ANUNCIAÇÃO, 2017; RUANO \& CURSINO, 2015; SÃO BERNARDO, 2016), destacamos a carência de políticas públicas e linguísticas que garantam o ensino de português brasileiro aos imigrantes deslocados forçados. Perante esta situação, o ensino do português para imigrantes ocorre por meio de ONGs e outras instituições que promovem aulas de língua, ministradas, na maioria das vezes, por professores voluntários, que não possuem formação para exercer a docência. Em tal contexto, os materiais didáticos ocupam lugar central no processo de ensino de língua de acolhimento, servindo como currículo orientador dos cursos e formador do professor. Por este motivo, salientamos a necessidade de repensar constantemente os materiais já disponíveis, a fim de aprimorá-los e, por este viés, auxiliar o acolhimento em língua portuguesa.

No tocante às orientações sistematizadas para o ensino de PLAc, São Bernardo (2016), em sua tese, destaca a necessidade de que os cursos 
se estruturem a partir das necessidades mais urgentes dos imigrantes deslocados forçados, relacionado ao trabalho, acesso à saúde e à educação, desenvolvendo, assim, a competência comunicativa com enfoque intercultural do aprendente. Para isso, a autora faz referência ao desenvolvimento de uma consciência cultural crítica dos alunos. Nessa perspectiva, entendemos o letramento ideológico, desde os primeiros contatos com a língua portuguesa, como crucial para o ensino socialmente engajado de PLAc. Em adição, São Bernardo (2016) ressalta que os professores de PLAc devem ser interculturalmente competentes, entretanto, deve-se levar em consideração que a maioria desses não possuem formação para ensinar línguas, fato que reforça a necessidade de que o material didático seja pensado para explicitar tais questões.

Compartilhando da definição de Acolhimento em línguas, trazida por Anunciação (2017), entendemos como imprescindível que o ensino de português aconteça por meio de um letramento ideológico, possível através do entendimento da linguagem como situada na história e na sociedade, como fruto de interação entre sujeitos (BAKHTIN, 1997). Para que isso ocorra, deve-se considerar as necessidades do público aprendiz, que compreende, além da comunicação imediata em espaços públicos/sociais, a compreensão cultural do novo ambiente onde estão inseridos. Nas palavras de Mendes (2010, p. 68), "usar uma língua é também ser e agir socialmente através dela" e, por isso, acreditamos que o ensino na perspectiva de acolhimento viabiliza a aprendizagem da língua alvo atrelada à compreensão e posicionamento sociocultural dos envolvidos. Para atender a tais características de ensino que valorizam as relações interpessoais e o intercâmbio cultural, é essencial que os alunos sejam sujeitos atuantes em sua aprendizagem, capazes de refletir criticamente sobre sua cultura e o cotidiano. Com o intuito de contribuir com a área de ensino de PLAc, no tocante aos materiais didáticos, realizamos a análise da apostila Portas Abertas, tema dos tópicos a seguir.

\section{Metodologia}

Para a análise do material didático, elaboramos critérios a partir de seis pontos a serem levados em consideração. Cabe ressaltar que esses critérios foram adaptados de um trabalho de análise de material didático (OLIVEIRA, 2017), bem como do texto de Bulla, Lemos e Schlatter (2012), sendo eles:

1. Temática de cada unidade didática e relevância para o perfil de 
aluno, com foco na unidade $\mathrm{n}^{\circ} 6$ da apostila didática Portas Abertas;

2. Tipos de sequências de tarefas;

3. Enunciados das tarefas e orientações contidas para professores e alunos;

4. Gêneros do discurso de recepção e de produção e relação com tema da unidade;

5. Textos autênticos;

6. Concepções de letramentos subjacentes às tarefas.

Para melhor explicitar o foco de nossa análise, vale retomar cada um dos critérios: primeiramente, analisamos as temáticas e conteúdos propostos nas nove unidades que compõem a apostila, no intuito de refletir sobre a adequação dos temas de estudo ao contexto de acolhimento em línguas para imigrantes deslocados forçados. Em relação ao segundo critério, focamos na unidade $n^{\circ} 6$, nomeada "Quantas compras!", a qual é analisada extensivamente ao longo do trabalho. Ao atentarmos para os tipos de sequências de tarefas, analisamos se estas apresentam relação entre si, propondo uma progressão de conhecimentos mobilizados para a compreensão de leitura e escrita, além de avaliar a pertinência de atividades gramaticais e de reflexão linguística no estudo de textos.

O critério três busca analisar os enunciados das tarefas, visto que devem ser claros e explicativos para que conduzam o trabalho do professor e do aluno. No quarto critério, analisamos os gêneros do discurso propostos em atividades de leitura e escrita, para que possamos identificar características sobre o modelo de letramento que subjaz à tarefa. $\mathrm{O}$ critério cinco identifica os textos autênticos que constituem as tarefas da sexta unidade da apostila Portas Abertas (2017), visto que nossa investigação sobre o letramento subjacente às tarefas também se relaciona à pertinência da escrita no uso real da linguagem. O último critério reúne as características relativas aos demais exercícios que constituem a unidade em foco, para que tenhamos informações suficientes para refletir sobre os traços de letramento ideológico ou autônomo das tarefas. Os critérios elaborados são analisados conjuntamente, seguindo a sequência de tarefas e atividades propostas na apostila.

Anteriormente à análise, esclarecemos nosso entendimento sobre alguns conceitos dos quais nos valemos com recorrência. Tarefa pedagógica é compreendida "como um convite para que ações sejam realizadas conforme uma sugestão (também expressa na tarefa) de enquadramentos de atividades futuras e sustentada por objetivos educacionais" (BULLA, 
LEMOS e SCHLATTER, 2012, p. 108), já atividades pedagógicas e exercícios estão implicados na realização da tarefa. Seguindo a perspectiva de análise adotada por Oliveira (2017, p. 30):

Dessa forma, neste trabalho, são analisadas as tarefas pedagógicas que podem apresentar exercícios - que estão dispostas no material, pois não se analisam dados de sala de aula com alunos e professores realizando atividades pedagógicas. Uma tarefa sempre é considerada por sua numeração, por exemplo 3.1, e o exercício faz parte desta tarefa.

Na próxima seção, passamos à análise da apostila Portas Abertas, partindo da discussão sobre sua totalidade para, então, enfocar na unidade $\mathrm{n}^{\circ} 6$.

\section{Análise do material}

Dado o crescente fluxo de imigrantes deslocados forçados que vêm chegando ao Brasil, encontramos materiais de ensino específico do português a este público, como exemplo, a apostila didática Pode Entrar: Português Brasileiro para Refugiadas e Refugiados da ACNUR/ONU. Entretanto, materiais com esta especificidade de ensino ainda são exíguos, enquanto que o número de aprendizes é crescente. Com essa mesma finalidade de ensino, merece destaque a apostila didática Portas Abertas, disponível gratuitamente para download, fruto do trabalho realizado pelo centro de línguas da USP, juntamente à Secretaria Municipal de Direitos Humanos e Cidadania (SMDHC) da cidade de São Paulo. Segundo informações disponíveis no site da prefeitura de São Paulo:

O Projeto "Portas Abertas: Português para Imigrantes", iniciativa compartilhada entre a Secretaria Municipal de Direitos Humanos e Cidadania e a Secretaria Municipal de Educação, tem como objetivo oferecer o ensino da língua portuguesa na Rede Municipal de Ensino em regiões de alta vulnerabilidade social da cidade, onde há pouca oferta de cursos de português e com maior incidência da população imigrante de São Paulo (PREFEITURA DE SÃO PAULO, online).

O material didático em análise consiste em uma apostila didática cujos interlocutores projetados são os alunos aprendizes de PLAc. Não encontramos indicação sobre o nível de proficiência do público de destino, mas podemos inferir, ao analisarmos os títulos e os conteúdos das unidades, que se proponha em sua totalidade ao nível básico, no qual o aluno possui pouco ou nenhum conhecimento da língua portuguesa, mas que é alfabetizado em sua língua materna ou em outras línguas que não o português, visto que o 
foco das tarefas não recai sobre a alfabetização. Sobre a criação do material, ainda ressaltamos que este é fruto da "reunião do trabalho de três grupos de professoras e professores, os quais doaram as partes mais bem-sucedidas de sua experiência para sua confecção" (Portas Abertas, 2017, p. 3), vinculados à USP e à UNIFESP. O material é estruturado por nove unidades, compostas pelos seus respectivos conteúdos, como exposto na tabela 1:

\begin{tabular}{|l|l|}
\hline Título da unidade & Conteúdos \\
\hline Introdução & Bandeira do Brasil, cores e expressões de sala de aula \\
\hline Cheguei! & $\begin{array}{l}\text { Alfabeto, Saudações, Despedidas, Expressões de Po- } \\
\text { lidez, Numerais }\end{array}$ \\
\hline Quem sou eu? & $\begin{array}{l}\text { Apresentação Pessoal, Nacionalidades, Dia a Dia; } \\
\text { Pronomes Pessoais, Preposições DE e EM, Artigos } \\
\text { Definidos; Direito à Documentação }\end{array}$ \\
\hline É hora de trabalhar! & $\begin{array}{l}\text { Profissões, Experiência e Currículo Profissionais; } \\
\text { Pretéritos Perfeito e Imperfeito do Indicativo, Advér- } \\
\text { bios de Tempo; Direito ao Trabalho Decente }\end{array}$ \\
\hline $\begin{array}{l}\text { E agora, como eu } \\
\text { chego? }\end{array}$ & $\begin{array}{l}\text { Como chegar: Transporte Público em São Paulo, Bair- } \\
\text { ros e Locais da Cidade; Futuro do Presente do Indica- } \\
\text { tivo, Verbos IR e VIR; Direito ao Transporte }\end{array}$ \\
\hline Quantas compras! & $\begin{array}{l}\text { Alimentação, Vestuário, Compras; Receita Culinária, } \\
\text { Tipos de Restaurantes, Imperativo; Direito à Banca- } \\
\text { rização }\end{array}$ \\
\hline $\begin{array}{l}\text { Meu corpo, minha } \\
\text { lei! }\end{array}$ & $\begin{array}{l}\text { Saúde e Corpo Humano, Descrição Física, Pronomes } \\
\text { Reflexivos e Possessivos, Direito à Saúde, Direito da } \\
\text { Mulher }\end{array}$ \\
\hline $\begin{array}{l}\text { Família ê, família ah, } \\
\text { Família! }\end{array}$ & $\begin{array}{l}\text { Família e Relações Sociais, Tipos de Relacionamen- } \\
\text { tos, Parentescos, Direito à Educação }\end{array}$ \\
\hline $\begin{array}{l}\text { Um pouco de Geo- } \\
\text { se lugar... }\end{array}$ & $\begin{array}{l}\text { Características das Regiões do Brasil; Ciclos Econô- } \\
\text { micos e Formação da Sociedade Brasileira; Discu- } \\
\text { tindo Racismo e Questões Indígenas: Expressões de } \\
\text { Argumentação; Preposições POR, PARA e ATÉ, Voz } \\
\text { Passiva, Pronomes Pessoais, Presente do Subjuntivo, } \\
\text { Conjunções Subordinativas }\end{array}$ \\
\hline
\end{tabular}

Tabela 1: Temas e conteúdos da apostila Portas Abertas (2017) 
De acordo com o texto de abertura do material didático, o entendimento sobre o ensino de PLAc das autoras diz respeito ao aprendizado da língua portuguesa para a participação social dos imigrantes, tendo como objetivo propiciar o "aprendizado pelo caminho do esclarecimento dos Direitos dos Migrantes, pelo domínio e conhecimento do espaço, pela inserção digna na sociedade e no trabalho, pela troca intercultural" (Portas Abertas, 2017, p. 3). Em uma análise geral da apostila, fica evidente a preocupação com as temáticas relevantes ao contexto de PLAc, relacionadas à documentação, à procura por trabalho, locomoção e educação, entre outros, temas relevantes nesse tipo de material (SÃO BERNARDO, 2016). Destacamos esse aspecto, aparentemente óbvio, visto que é necessário que materiais de PLAc levem em conta os contextos de uso da língua que o aprendiz vivenciará, uma vez que alguns materiais de ensino de português, que não possuem este fim específico, tratam de questões por vezes fora da realidade de imigrantes deslocados forçados, por exemplo, perguntas relativas ao tempo que o imigrante passará no Brasil (muitos não têm perspectiva de voltar aos seus países) e quais praias e locais turísticos do Brasil irão visitar nas próximas férias (esses sujeitos geralmente migram em busca de trabalho, para garantir sua sobrevivência, não a passeio).

Nessa perspectiva, a escolha por temáticas relevantes ao perfil dos aprendizes se relaciona ao entendimento freiriano sobre educação, partindo das temáticas que fazem parte das vivências dos alunos, para que o aprendizado seja significativo, mas sem se restringir somente ao já conhecido (FREIRE, 1991). Ainda sobre a estruturação geral das unidades, ressaltamos como positiva a escolha de textos que abordam os direitos dos imigrantes, ao passo que reforçamos a necessidade de também se abordar os seus deveres no Brasil, como já apontado por Oliveira (2017). Compreendemos que textos como "Direito da Mulher" e "Direito ao Trabalho Decente" implicam um trabalho com os deveres, contudo, é imprescindível que tarefas com esta finalidade de discussão venham explícitas por meio de enunciados, para que o professor atente ao seu tratamento.

Ao nos determos sobre os conteúdos previstos em cada uma das unidades temáticas, encontramos a presença de subtemáticas (direito ao transporte; direito à bancarização), conteúdos linguísticos (pronomes pessoais, preposições) e gêneros discursivos (receita culinária, currículo profissional). Considerando os objetivos propostos pelas idealizadoras da apostila, avaliamos como profícuo se os conteúdos previstos dentro de cada unidade se estruturassem por gêneros discursivos, compreenden- 
do as ações que os aprendizes realizarão em suas esferas de participação social, para se ensinar o português de forma significativa e socialmente relevante aos imigrantes. Assim, os conteúdos gramaticais e os recursos linguísticos seriam selecionados a partir da sua relevância para a produção de determinados gêneros discursivos relacionados à temática da unidade. Esta sugestão de maior exploração e de reestruturação do material já presente na apostila permitiria que textos autênticos apresentados na Portas Abertas fossem estudados e melhor compreendidos pelos alunos, em busca de um letramento ideológico (STREET, 1984; 2003).

Outra característica do material, importante para nossa análise, diz respeito aos textos selecionados para o material. De acordo com o que as autoras esclarecem sobre a apostila, "em seus capítulos são apresentados textos sobre direitos dos imigrantes extraídos do Guia de Acesso a Direitos para Imigrantes e Servidores, publicado pela Secretaria Municipal de Direitos Humanos e Cidadania de São Paulo" (Portas Abertas, 2017, p. 3). De fato, a maioria das unidades apresentam textos autênticos, característica desejável e positiva na busca pela participação cidadã dos imigrantes.

No entanto, em alguns desses textos, não há tarefas de estudo do gênero discursivo, deixando esta criação a cargo do professor que, sem orientações, poderá não saber produzir tarefas. Outros textos autênticos apresentados ao longo da apostila, e que estão acompanhados de tarefas didáticas, apresentam-se destituídos de sua fonte original, ou seja, o aluno não saberá o local de publicação do texto (é um texto de orientação publicado na página da prefeitura de São Paulo? é a propaganda de um banco?). Em nossa perspectiva de análise, ao pensarmos em um letramento que considera o contexto autêntico de circulação dos textos, é relevante que esta fonte seja explicitada aos alunos, assim, pode-se explorar questões como a autoria do texto, público de destino e efeitos de sentido pretendidos a partir da linguagem utilizada.

\subsection{Análise do material: unidade $n^{\circ} 6$}

Após a discussão geral sobre as unidades da apostila, bem como sobre as características que nelas se repetem, optamos, como recorte, pela análise da unidade, intitulada "Quantas compras!". Compreendemos a limitação de se analisar somente parte do material; no entanto, entendemos que, como o nosso foco são as tarefas de leitura e escrita, essas estão mais presentes nas últimas unidades do material didático. As cinco unidades 
anteriores apresentam tarefas mais estruturais para o estudo da língua, característica que se justifica nos primeiros contatos de aprendizagem de uma língua adicional, visto que estão em processo de criação de instrumentos para interagir por meio de gêneros do discurso mais complexos (BRESSAN, 2002). Não obstante, ressaltamos que

(...) levar em conta o uso da linguagem, os gêneros do discurso e a variação linguística em sala de aula não é uma orientação restrita apenas a níveis intermediários ou avançados de língua adicional, já que usamos a linguagem por meio de gêneros do discurso todo o tempo, mesmo em situações com complexidade linguística que poderíamos classificar como menor, como cumprimentos, por exemplo, que costumam ser trabalhados nos níveis iniciais (DILLI, SCHOFFEN e SCHLATTER, 2012, p. 178).

Além disso, a escolha pela sexta unidade da apostila é justificada pelas tarefas com potencial para promover um letramento ideológico já presentes no material (STREET, 1984, 2003; KLEIMAN, 1995), além de se aproximarem mais das concepções de linguagem como forma de interação (BAKHTIN, 1997) e acolhimento em línguas (ANUNCIAÇÃO, 2017), que defendemos como producentes no ensino de português no contexto de PLAc. No aspecto mais amplo, a unidade composta por 16 páginas (p. 50-66) trata de uma temática relevante ao ensino de PLAc, as compras, partindo da perspectiva do aprendiz e considerando situações que ele potencialmente vivenciará desde os primeiros momentos de inserção no Brasil. Cabe a ressalva de que o letramento não deve ser apenas funcional, mas também crítico, portanto, temáticas mais reflexivas - menos voltadas para a utilidade - também são necessárias no ensino de PLAc (PAPEN, 2005).

A unidade inicia com uma atividade de vocabulário que serve de insumo e construção do conhecimento prévio sobre alimentos. Posteriormente às atividades voltadas à construção de vocabulário, há uma atividade que relaciona o conteúdo estudado ao seu uso, solicitando que os alunos conversem com os colegas e façam perguntas como: "Como é a comida do seu país? Quais são os principais ingredientes?”. Neste início da unidade, é possível notar que se estabelece uma sequência coesa entre as atividades, primeiramente com o estudo do vocabulário e, depois, com a mobilização do conteúdo estudado em uso. Dessa maneira, as tarefas anteriores servem como suporte para as subsequentes, conforme mostra a reprodução a seguir: 
5. O que você come na janta?

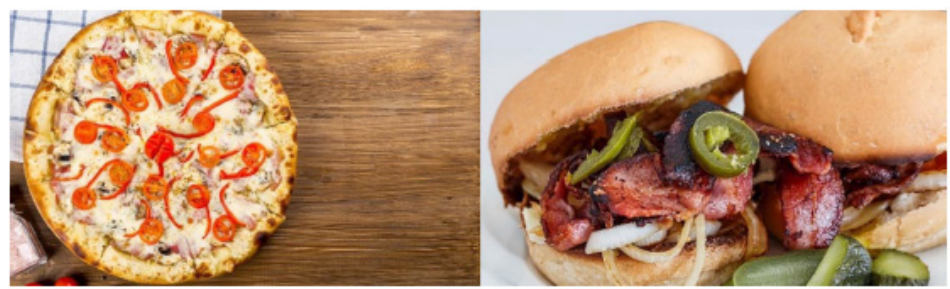

brigadeiro macarrão instantâneo lanche salada cuscuz feijoada chá

6. Fale com o colega:

- Como é a comida do seu país? Quais são os principais ingredientes?

Figura 1 - Insumo de vocabulário ( $n^{\circ}$ 5) e vocabulário em uso ( $n^{\circ}$ 6) (Portas Abertas, 2017, p. 52)

Na sequência, há um texto autêntico, uma propaganda de supermercado, seguido de perguntas que exploram sua compreensão de forma coerente com o que se espera na leitura do gênero discursivo, solicitando que os alunos produzam uma lista de compras a partir da propaganda, além de analisar o preço dos produtos. Os textos autênticos permitem que os alunos estudem a língua a partir de situações com as quais se deparam no seu cotidiano para além da sala de aula, que estão em circulação no dia a dia, mobilizando, assim, a linguagem para realizar ações no mundo (CLARK, 2000). As atividades de conversa em pares e o trabalho realizado com a propaganda indicam a concepção de linguagem como forma de interação presente na apostila, alinhada à concepção dialógica da linguagem (BAKHTIN, 1997). Neste viés, entendemos que há marcas de uma orientação ideológica de letramento.

Prossegue-se com a temática sobre compras no material, contudo, não há um novo enunciado que designe uma tarefa para as atividades e exercícios que seguem. No que se refere ao tratamento de questões gramaticais, há um exercício estrutural de conjugação de verbos no presente do indicativo, o que consideramos pertinente uma vez que aborda verbos estudados anteriormente na unidade. Os exercícios que seguem têm como objetivo que os alunos pratiquem os verbos estudados através da criação de frases e por meio de atividade de completar um diálogo criado para fins didáticos. Em relação à criação de textos para o ensino, compreendemos a dificuldade de se encontrar textos autênticos adequados ao trabalho 
com níveis iniciantes; no entanto, a fim de promover um letramento ideológico e significativo aos estudantes, tarefas de produção oral poderiam ser adicionadas para que, em pares, os alunos utilizassem as estruturas e o vocabulário aprendido, bem como a conjugação de verbos.

Na página 57 da apostila Portas Abertas (2017), um diálogo é apresentado na forma escrita sem a presença de um enunciado que indique ao aluno ou ao professor o que fazer com aquele texto: leitura silenciosa? simulação de diálogo?

Na loja de eletrodomésticos...

Bom dia, posso ajudar?

Bom dia, eu quero escolher uma geladeira.

Hoje as geladeiras estão em liquidação.

No caixa...

Mais alguma coisa?

Não, só a geladeira mesmo.

São $1.230,00$ reais. A senhora pode fazer em até 10 vezes

de 123 reais. Ou à vista, com um desconto de 100 reais.

Então à vista fica 1.130 reais?

Isso!

Ok, vou pagar à vista.

Figura 2 - Diálogo sem enunciado que designe tarefa (Portas Abertas, 2017, p.57)

Observamos que esta seria uma atividade oportuna para se trabalhar com a compreensão oral, porém, acreditamos que a opção por não utilizar áudios se deu devido à impossibilidade de produzi-los especificamente para que acompanhasse a apostila. Não obstante esse impedimento com o trabalho de compreensão oral, seria possível que o diálogo viesse seguido de outra tarefa que possibilitasse o uso das estruturas e de novas informações, através de uma atividade de role play entre os alunos, em que um dos estudantes seria o vendedor de uma loja e o outro, comprador. Para professores de português como língua adicional, a elaboração desta tarefa para o texto provavelmente seja intuitiva, contudo, vale lembrar que professores com formação não constituem a maioria dos docentes em contextos de PLAc.

No desenvolvimento da unidade, há uma receita culinária, texto coerente com as atividades anteriores, relacionando-se à temática de alimentação e compras. Apesar de ser um gênero relevante para a temática, novamente falta um enunciado que o situe dentro de uma tarefa; assim, professor e aluno não têm orientações sobre como se aproximar do texto, 
tampouco sobre qual o objetivo de leitura. Além disso, a tarefa que segue a receita é a conjugação de verbos no imperativo. A explicação sobre este modo verbal apresentada na apostila se limita a um quadro explicativo de suas funções, e depois, propõe exercícios de conjugação:

\section{IMPERATIVO}

Os verbos destacados na receita acima estão no modo imperativo (coloque, adicione, refogue, retire, abra, etc.). Esse modo é usado para dar ordens, conselhos, orientações (vire à direita), sugestões, alertas ou avisos.

$\begin{array}{clll}\text { IMPERATIVO } & \text { Colocar } & \text { Bater } & \text { Servir } \\ \text { Voce } & \text { Coloque } & \text { Bata } & \text { Sirva } \\ \text { Voces } & \text { Coloquem } & \text { Batam } & \text { Sirvam }\end{array}$

Coloque os verbos abaixo no imperativo seguindo o modelo acima:

\begin{tabular}{l|l|l|}
\cline { 2 - 3 } Verbo & \multicolumn{1}{c|}{ Singular } & \\
Cortar & & \\
Diluir & & \\
Bater & & \\
Despejar & & \\
Cozinhar & & \\
Fritar & & \\
Assar & & \\
Mexer & & \\
Abrir & & \\
\hline
\end{tabular}

Figura 3 - Funções do imperativo Portas Abertas, 2017, p.58)

Tendo em vista o desenvolvimento do letramento ideológico dos alunos, sugerimos que se explore melhor este modo verbal, considerando as implicações de utilizar o imperativo em língua portuguesa. Quais os efeitos de sentido de se fazer um pedido ou uma recomendação empregando o imperativo, por exemplo, seriam reflexões linguísticas possíveis de se fazer com alunos de nível iniciante.

Para que o texto de recepção, receita, seja colocado em prática, há uma atividade para que se ensine uma receita ao colega, orientada pelo enunciado "Agora ensine uma receita para um colega, utilizando verbos no imperativo. O seu colega vai te ensinar uma receita também" (Portas Abertas, 2017, p. 58). Reiteramos o aspecto positivo da apostila de trabalhar em diversos momentos com a produção oral em pares entre alunos; no entanto, a realização desta tarefa depende da maneira que o texto do gênero receita foi trabalhado anteriormente, visto que a recepção do gênero implica diretamente em sua produção. A falta de orientações expressas em um enunciado, em forma de tarefa didática, compromete a produção do texto. Sugerimos que o trabalho com receitas culinárias poderia ser 
expandido através de tarefa de compreensão oral, por meio de vídeos disponíveis no Youtube, que não exijam o pagamento de direitos autorais ao serem vinculados a materiais didáticos sem fins comerciais. Esta recomendação de expansão do trabalho com o texto poderia vir expressa, tendo em conta o perfil do professor.

Ainda na esteira sobre alimentação e consumo, a apostila apresenta um compilado de breves informações sobre tipos de restaurantes. Em relação a esses textos breves, observa-se, mais uma vez, a falta de um enunciado que oriente a leitura, além de ser um texto adaptado sem referência à fonte original. Mesmo que haja coerência e progressão nas atividades, este texto poderia ser melhor aproveitado se localizado em uma tarefa de ensino que objetivasse sua compreensão e, posteriormente, o uso do conteúdo estudado em produções escritas.

Chamamos a atenção para o bloco de atividades que inicia na página 59 e vai até a página 62 da apostila Portas Abertas (2017). Há o trabalho com diálogos referentes a pedidos de alimentos pelo telefone e, para isso, apresenta-se um diálogo, a fim de que os alunos leiam e localizem informações

\section{PEDINDO COMIDA POR TELEFONE}

17. Leia o diálogo e responda as questões:

- Boa noite, gostaria de fazer um pedido.

- Boa noite! Pode falar!

- Quero uma pizza meia marguerita e meia frango com catupiry e uma refrigerante grande.

- Borda recheada?

- Quais as opções?

- Catupiry e cheddar.

- Pode ser com catupiry. Quanto fica?

- A pizza fica $R \$ 30,00$, com borda recheada fica $R \$ 33,00$, mais a refrigerante que é R\$7,00. Qual o endereço para entrega?

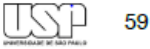

- Estrada Presidente Juscelino Kubitschek de Oliveira, número 76

- Qual a forma de pagamento?

- Dinheiro. Troco para R\$50,00.

- Ok. Em no máximo 40 minutos o motoboy entregará.

- Obrigada. Boa noite!

- Boa noite, senhor!

a.) Qual o sabor da pizza pedida pelo cliente?

b.) Você gosta de pizza? Como seria o seu pedido?

Figura 4 - Localização de informações no texto (Portas Abertas, 2017, 2017) 
Após isso, segue uma atividade de repetição da estrutura para que se faça um pedido de alimentos por escrito, conjugação de verbos relacionados ao tema "pedidos", ordenação de partes do diálogo de um pedido e, ao final, há uma proposta de produção de texto a partir do enunciado "Sua vez! Você pode nos contar como é a alimentação no seu país? É muito diferente da comida brasileira?" (Portas Abertas, 2017, p. 62). Consideramos que um ensino que considera o texto em sua totalidade deva estabelecer coerência entre o gênero de recepção, aquele que os alunos estudam, e o gênero de produção, o que se solicita que o aluno produza. Assim, para que houvesse maior alinhamento nesta sequência de atividades, sugerimos que se adicionasse atividades com diálogos de pedido de comida a serem produzidos oralmente pelos alunos, visto que este é o gênero trabalhado extensivamente no bloco de tarefas. Inferimos que essa sequência de exercícios tenha tarefas de produção oral subentendidas, ficando a cargo do professor desenvolve-las; por este motivo, salientamos a importância da existência de caderno para professores.

Outros aspectos positivos podem ser ressaltados em linhas gerais, comuns a materiais didáticos de ensino de línguas adicionais. Por exemplo, os numerais cardinais são trabalhados a partir da discussão sobre preços dos alimentos, ou seja, de maneira contextualizada; há momentos para reflexão sobre a variação linguística através de glossário com palavras utilizadas em diferentes regiões do Brasil para designar determinados alimentos. No que concerne à análise crítica das atividades apresentadas na apostila, cabe apontar que ao final da discussão sobre alimentação, o aluno deve contar como é a alimentação no seu país, por meio das orientações dadas no enunciado "Sua vez! Você pode nos contar como é a alimentação no seu país? É muito diferente da comida brasileira?". Consideramos que falta, para a realização desta ação discursiva, retomar os recursos linguísticos estudados na UD, para que o aluno saiba como dizer o que tem para dizer. Além disso, tendo em vista a busca por um modelo ideológico de letramento, é interessante que os estudantes entrem em contato com gêneros discursivos que ultrapassem aqueles com os quais têm contato cotidianamente, como exemplo para a unidade em análise, gráficos que indicam os hábitos alimentares dos brasileiros.

A unidade 6 ainda apresenta a subtemática "vestimentas", na qual caberia o trabalho com textos autênticos, como anúncios e propagandas. A apostila se vale novamente do recurso de textos adaptados e/ou criados para fins didáticos para explicar formas de pagamento e tamanhos de rou- 
pas no Brasil, recurso melhor aproveitado se acompanhado de uma tarefa para que professor e aluno saibam o que fazer com o texto. Infelizmente, sem esta orientação, corre-se o risco de que o professor oriente a leitura em voz alta e esta seja a única ação realizada com o texto, destituindo-o de suas características comunicativas.

A unidade se encerra com um texto criado com fins didáticos sobre direito à bancarização. Destacamos o caráter positivo do tratamento deste texto, acompanhado das perguntas de compreensão leitora e de pós-leitura:

\section{Atençao:}

Tem muitos bancos em São Paulo, mas há dois que estão preparados para atender a população de migrantes ou de refugiados:

\begin{tabular}{|c|c|}
\hline $\begin{array}{l}\text { Caixa Econômica Federal } \\
\text { Facilita o acesso à bancarizaçăo de } \\
\text { migrantes vindos de Estados-Parte do } \\
\text { Mercosul e Associados }\end{array}$ & $\begin{array}{l}\text { Banco do Brasil } \\
\text { Facilita o acesso à bancarizaçăo de } \\
\text { migrantes vindos dos outros paises que } \\
\text { năo os do Mercosul }\end{array}$ \\
\hline $\begin{array}{l}\text { Documentação para abrir conta: } \\
\text { 1. RNE ou Protocolo de Solicitaçăo de } \\
\text { Refúgio } \\
\text { 2. Documento de Identificaçăo Original } \\
\text { (do país de origem) } \\
\text { 3. CPF } \\
\text { 4. Comprovante de residência } \\
\text { 5. Comprovante de renda (exceto para } \\
\text { Conta Caixa Fácil e Poupança Caixa) }\end{array}$ & $\begin{array}{l}\text { Documentação para abrir conta: } \\
\text { 1. RNE ou Passaporte ou CNH ou } \\
\text { Carteira de Trabalho } \\
\text { 2. CPF } \\
\text { 3. Comprovante de residencia (com no } \\
\text { máximo } 90 \text { dias) } \\
\text { 4. Duas referencias: nome e telefone }\end{array}$ \\
\hline $\begin{array}{l}\text { Mais informaços em: } \\
\text { www.caixa.qov.br }\end{array}$ & $\begin{array}{l}\text { Mais informaços em: } \\
\text { www.bb.com.br }\end{array}$ \\
\hline
\end{tabular}

\section{Responda:}

a.) Qual dos dois bancos é melhor para você?

b.) Qual é a diferença entre conta corrente e conta poupança?

c.) No seu país é fácil ter um cartão de crédito?

d.) Como você faz para não ter dívidas com o cartão de crédito?

Figura 5 - Texto adaptado para fins didáticos (Portas Abertas, 2017)

Tendo em vista o objetivo desta análise, de contribuir com a extensão do material, salientamos os pontos positivos, mas também tecemos sugestões para sua melhoria, por isso, consideramos que os textos 
informativos sobre cartões bancários deveriam ser autênticos. No intuito de facilitar o texto para o aluno, muitas vezes este é destituído de suas características reais e mais importantes; se o objetivo de ensino é promover o modelo ideológico de letramento, é preciso que se pense a origem dos textos e para quem foram escritos, ou seja, o contexto dessa prática social.

A fim de sistematizar a discussão sobre a apostila didática, retomamos os pontos positivos apresentados na Portas Abertas (2017). Pode-se afirmar que as atividades propostas na unidade 6 apresentam sequência e encadeamento lógico, a fim de dar suporte à progressão de aprendizagem do estudante. Os recursos gramaticais são coerentes com a temática e com os usos de textos propostos, no entanto, é importante que eles sejam retomados no momento de produções textuais. Em diversos momentos, propõe-se a interação oral e escrita entre pares de alunos, o que permite a prática oral da língua em situações comunicativas. Sem deixar de considerar os notáveis aspectos positivos do material, fazemos a ressalva de que não há tarefas de ensino que considerem um mesmo gênero textual no momento de recepção e de produção, além da falta de enunciados que se configurem como tarefas e orientem claramente o que deve ser feito com o texto em pauta. Em relação aos textos, esses poderiam ser mantidos tal como aparecem em seu contexto real de circulação e publicização. Dessa forma, acreditamos que seja possível alcançar um maior comprometimento com o letramento ideológico dos aprendizes, bem como melhor orientação de trabalho aos professores.

\section{Considerações finais}

Por meio da análise e discussão feitas sobre a apostila didática Portas Abertas (2017), compreendemos que o material tem potencial para promover um letramento ideológico que estimule a participação cidadã dos alunos, no entanto, visto que muitas das orientações para tarefas estão subentendidas, cabe ressaltar que professores voluntários de PLAc, sem formação para o ensino de línguas, não irão além do "já posto" no material didático, comprometendo sua proposta de conduzir "o aprendizado pelo caminho do esclarecimento dos Direitos dos Migrantes, pelo domínio e conhecimento do espaço, pela inserção digna na sociedade e no trabalho, pela troca intercultural" (Portas Abertas, 2017 , p. 3). Esclarecemos, ainda, que oferecer materiais acompanhados de instruções para professores sem formação insere-se nas ações das horizontalidades, sem o intuito de reforçar o contexto de voluntariado que 
caracteriza o acolhimento linguístico, mas sim a partir da compreensão de que ações horizontais têm o potencial de influenciarem a tomada de decisões que se inscrevem nas verticalidades. Desta maneira, melhorias focadas no ensino de língua, pautadas por discussões teóricas, podem fomentar a criação de políticas linguísticas relativas ao PLAc que se constituam como transversais, perpassando as esferas verticais e horizontais (BIZON; CAMARGO, 2018; SANTOS, 2001).

Para além da discussão apresentada sobre acolhimento em línguas, reiteramos que o ensino "instrumental" para preenchimento de currículos e formulários não é ensino crítico do uso da linguagem. Dessa forma, ainda que se aborde questões urgentes enfrentadas pelos imigrantes deslocados forçados, vale destacar que este trabalho deve ser feito no intuito de habilitá-lo a usar criticamente a língua, pensando sobre e através dela; por isso a importância do letramento ideológico, que deve iniciar nos níveis básicos e se perpetuar na jornada de aprendizagem do imigrante, permitindo que este sujeito siga, se assim desejar, em contextos de ensino especializados, como o universitário.

Neste viés, a Portas Abertas promove um ensino além do "instrumental", abordando direitos dos imigrantes e promovendo a participação cidadã dos aprendizes, entretanto, como qualquer material didático, melhorias podem ser implementadas. Reiteramos nossa consciência sobre as limitações deste trabalho, por focarmos na análise minuciosa de somente uma das unidades da apostila, assumindo a necessidade e o interesse futuro em realizar uma análise completa, acompanhada de sugestões para o aperfeiçoamento das unidades didáticas através dos critérios aqui apresentados. Em complemento, reforçamos a urgência de se investir, no contexto de produção de trabalhos acadêmicos, em análise e criação de materiais didáticos de PLAc, visto que esses são, via de regra, elaborados e distribuídos gratuitamente. Por isso, entendemos que devemos unir nossos esforços para complementar tais materiais, produzindo, com certa urgência, cadernos de orientação para professores voluntários.

Vale ressaltar que, apesar da necessidade de se criar cadernos de professores para que as aulas de PLAc sejam melhor organizadas e tragam mais benefícios aos alunos, é fundamental que o ensino de língua a imigrantes deslocados forçados e acolhidos no Brasil esteja previsto na agenda de políticas linguísticas, e que seja fomentado pelo Estado de forma remunerada, para que profissionais com formação possam atuar 
neste contexto, qualificando-o. Defendemos a criação de cadernos do professor não para engessar a prática docente, mas sim para oferecer subsídios para que os professores também tenham a liberdade de co-construir o material didático, através de implementações e modificações conscientes.

Nesta análise, nos empenhamos em construir reflexões, sobre as tarefas didáticas, com base nos conceitos de letramento ideológico e autônomo (STREET, 1984, 2003; KLEIMAN, 1995), a fim de dialogar com os pesquisadores que se dedicam a elaborar materiais de ensino de Português como Língua de Acolhimento. Almejamos, assim, sugerir melhorias dos bons materiais didáticos de PLAc, já disponíveis e acessíveis aos professores, como é o caso das apostilas Portas Abertas (2017) e Pode Entrar (2015). Além disso, como meta que permeia a discussão aqui apresentada, desejamos fomentar reflexões que guiem trabalhos futuros na criação de livros de orientação aos professores que utilizarão apostilas como a Portas Abertas. 


\section{LITERACY MODELS UNDERLYING IN A TEACHING MATERIAL OF PORTUGUESE AS A WELCOMING LANGUAGE}

\section{ABSTRACT}

In view of the necessity of improving Portuguese as a Welcoming Language (PLAc) teaching, in this work we analyze the underlying concepts of reading and writing in tasks and activities of Portas Abertas (REINOLDES; MANDALÁ; AMADO, 2017), thinking of how students are prepared to the social uses of writing and reading by this teaching material. In the analysis methodology, we defined criteria which concern the aspects of didactic material, such as the selected discursive genres and their treatment in tasks that guide the work with the text, from the orientations of Bulla, Lemos and Schlatter (2012). It was possible to identify, by focusing on one of the didactic units, tasks aligned with the autonomous model of literacy, as well as other aligned with the ideological model of literacy (KLEIMAN, 1995; STREET, 2003), results that highlight the positive points of the teaching material, and, indicate aspects to be potentialized through reformulations of activities and creation of tasks. From the critical reading of this didactic material, we emphasize the importance of Portuguese as a Welcoming Language teaching materials being followed by teacher's materials, with a view to helping the teacher to conciliate the mishaps that are found in this context, as well as to promote a teaching practice concerned with citizen participation of the forced imigrants.

KEYWORDS: Literacy; Teaching material; Portuguese as a Welcoming Language.

\section{REFERÊNCIAS}

AMADO, R.S. O ensino de português como língua de acolhimento para refugiados. In: Sociedade Internacional de Português Língua Estrangeira - SIPLE, v. 7, 2014. 
AMARO, T.; FASSON, K.; FEITOSA, J.; MARRA, J.; MOREIRA, N.; PEREIRA, R. Pode Entrar: Português do Brasil para refugiadas e refugiados. São Paulo: ACNUR, Cáritas, Curso Popular Mafalda, 2015. Disponível em:

$<$ http://www.acnur.org/t3/fileadmin/Documentos/portugues/Publicacoes/2015/ Pode Entrar.pdf $>$. Acesso em 20 abril 2018.

ANÇÃ, M.H. Português: língua de acolhimento: entre contornos e aproximações. In: Congresso Internacional sobre História e Situação da Educação em África e Timor (Anais do evento). Lisboa, Universidade Nova de Lisboa, Faculdade de Ciências Sociais e Humanas, p. 1-6, 2003.

ANUNCIAÇÃO, R.F.M. Somos mais que isso: práticas de (re)existência de migrantes e refugiados frente à despossessão e ao não reconhecimento. Tese de doutorado. Universidade Estadual de Campinas, 2017.

BAKHTIN, M. Marxismo e filosofia da linguagem. São Paulo: Huditec, 1997, ed. 10 .

BIZON, A.C.C.; CAMARGO, H.R.E.C. Acolhimento e ensino da língua portuguesa à população oriunda de migração de crise no município de São Paulo: por uma política do atravessamento entre verticalidades e horizontalidades p. 712726 In: Migrações Sul-Sul. Baeninger et al. Campinas, SP: Núcleo de Estudos de População Elza Berquó - Nepo/Unicamp, 2018.

BRESSAN, C.G. A elaboração de tarefas com vídeos autênticos para o ensino de línguas estrangeiras. Dissertação de Mestrado em Estudos da Linguagem. Universidade Federal do Rio Grande do Sul, 2002.

BULlA, G. S. LEMOS, F. C.; SCHLATTER, M. Análise de material didático para o ensino de línguas adicionais a distância: reflexões e orientações para o design de tarefas pedagógicas. Revista Horizonte de Linguística Aplicada, v. 11, p. 103-135, 2012.

CABETE, M.A.C.S.S. O processo de ensino-aprendizagem do português enquanto língua de acolhimento. Dissertação de Mestrado em Língua e Cultura Portuguesa. Universidade de Lisboa, 2010.

CANAGARAJAH, S. Translingual practice: Global Englishes and cosmopolitan relations. New York: Routledge, 2013.

CLARK, H.H. O uso da linguagem. Cadernos de Tradução, Porto Alegre, n. 9, p. $55-80,2000$.

DILLI, C.; SCHOFFEN, J.R.; SCHLATTER, M. Parâmetros para a avaliação de produção escrita orientados pela noção de gênero do discurso. In: SCHOFFEN, J.R. et al. Português como Língua Adicional: reflexões para a prática docente. Porto Alegre: Editora Bem Brasil, 2012. 
FREIRE, P. A Educação na Cidade. São Paulo: Cortez Editora, 1991.

GROSSO, M.J.R. Língua de acolhimento, língua de integração. Horizontes de Linguística Aplicada, v. 9, n.2, p.61-77, 2010.

KLEIMAN, A. Modelos de letramento e as práticas de alfabetização na escola. In: . (org.) Os significados do letramento: uma nova perspectiva sobre a prática social da escrita. Campinas: Mercado de Letras, p. 15-61, 1995.

LOPEZ, A.P.A. Subsídios para o planejamento de cursos de Português como Língua de Acolhimento para Imigrantes Deslocados Forçados no Brasil. Dissertação de mestrado. Universidade Federal de Minas Gerais, 2017.

MENDES, E. Por que ensinar língua como cultura. In: SANTOS, P.; ALVAREZ, M. L. O (Orgs.). Língua e cultura no contexto de português língua estrangeira. Campinas: Pontes, p. 53-78, 2010.

OLIVEIRA, B.S. Construindo o ensino de português como língua de acolhimento: uma análise da apostila didática Pode Entrar. Trabalho de Conclusão de Curso. Universidade Federal do Rio Grande do Sul, 2017.

PAPEN, U. Literacy - what is it? Definitions, discourses and metaphors. In: 2005. . Adult literacy as social practice: more than skills. London: Routledge,

REINOLDES, M.; MANDALÁ, P.S.; AMADO, R.S. Portas Abertas: Português para imigrantes. São Paulo: USP, Secretaria Municipal de Direitos Humanos e Cidadania de São Paulo (SMDHC), 2017. Disponível em: $<$ http://www.prefeitura.sp.gov.br/cidade/secretarias/direitos_humanos/migrantes/noticias/index. php? $\mathrm{p}=247029>$. Acesso em 20 abril 2018.

ROJO, R. Materiais didáticos no ensino de línguas. In: MOITA LOPES, L. P. Linguística Aplicada na modernidade recente: Festschrift para Antonieta Celani. São Paulo: Parábola Editorial, 2013.

Letramentos múltiplos, escola e inclusão social (2009). São Paulo: Parábola Editorial, 2009.

RUANO, B.P.; CURSINO, C.A. O ensino de português brasileiro como língua de acolhimento: projeto PBMIH-UFPR - um estudo de caso. In: I Congresso Internacional de Estudos em Linguagem (Anais completos). Ponta Grossa, 2015. SANTOS, M. Por uma outra globalização: do pensamento único à consciência universal. Rio de Janeiro, RJ/ São Paulo, SP: Editora Record, 2001

SÃO BERNARDO, M.A. Português como língua de acolhimento: um estudo com imigrantes e pessoas em situação de refúgio no Brasil. Tese de doutorado em linguística. Universidade Federal de São Carlos, 2016. 
SILVA, R.C. Estudos recentes em Linguística Aplicada no Brasil a respeito de livros didáticos de língua estrangeira. RBLA. Belo Horizonte, v.10, n. 1, p. 207 226, 2010.

SOARES, M. Letramento e escolarização. In: RIBEIRO, Vera Masagão (org.). Letramento no Brasil. São Paulo: Global, 2003.

STREET, B. The future of 'social literacies'. In: Baynham, M.; Prinsloo, M. (ed.) The Future of Literacy Studies. Londres: Palgrave MacMillan, p. 21-37, 2009. . What's "new" in New Literacy Studies? Critical approaches to literacy in theory and practice. In: Current Issues in Comparative Education, Columbia University, v. 5(2), p. 77-91, 2003. Literacy events and literacy practices: Theory practice in the New Literacy Studies. In: Martin-Jones, M.; Jones, K. (eds.) Multilingual literacies: reading and writing different worlds. Amsterdam/Philadelphia: John Benjamins, p.17-29, 2000.

. Literacy in theory and practice. Cambridge: CUP, 1984.

Recebido: 01/05/2018

Aceito: 14/09/2018 